\title{
School of Optics in Vinh University: A Short History
}

\author{
Cao Long Van \\ Institute of Physics, University of Zielona Góra, Poland
}

(Received: 29 June 2010; accepted: 13 September 2010)

In 1985, as my work on the habilitation dissertation in the Center of Theoretical Physics (at the Polish Academy of Sciences) was coming to an end, a postgraduate student from the then Vinh Pedagogical High School came to me and asked me to find a supervisor for his doctoral thesis. His name is Nguyen Huy Cong, recently a professor of Technical University of Electricity Engineering in Hanoi. Without hesitation, I introduced him to a young outstanding physicist, a professor of Warsaw University, Krzysztof Wódkiewicz (Phot. 1) which was one of the best students of Professor Iwo Białynicki-Birula whose "scientific sons and grandsons", as one could see below, have been playing essential roles in the collaboration with Vinh University over the last twenty years. To me, it is an honor to be both his graduate and postgraduate student.

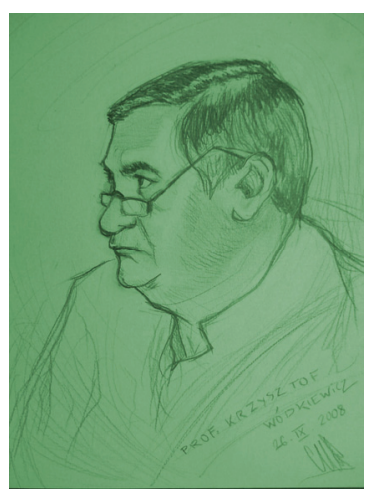

Phot. 1. Professor Krzysztof Wódkiewicz

Prof. I. Białynicki-Birula has always been in good terms with Vietnamese physicists. His friend from the time he spent in Dubna near Moscow is an outstanding Viet- namese physicist, professor Nguyen Van Hieu. They have even written a paper together. In 1990, he participated in the Workshop for Theoretical Physics organized by Professor Tran Huu Phat, another leader of Vietnamese Physics. Professor I. Białynicki-Birula was the scientific advisor for Prof. Phat's habilitation in Warsaw University 1976.

During the eighties, I participated in the programme of building atomic bombs directed by Prof. Phat. Fortunately, Vietnam gave up this crazy idea later. At that time, I developed the formalism of pregaussian noises introduced to quantum optics by K. Wódkiewicz and Joe Eberly (see my papers written with K.Wódkiewicz and Nguyen Huy Cong $[1,2])$. It was the time when I also collaborated with professor Marek Trippenbach, a "scientific grandson" of I. Białynicki-Birula, but this is another story which will be described later. After defending his thesis, Nguyen Huy Cong came back to Vietnam and continued his work in Vinh University. Just as other Vietnamese scientists of that time, he fell into a "black hole" and lost any contact with the world abroad. During one of my visits to Vietnam in 1989, he introduced me to the President of Vinh University who invited me to attend the 30-th anniversary celebration of that School (Phot. 2). I saw that although both living and working conditions were very bad (as seen in Phot. 3 of the most scientific place in the University, the "astronomical yard" with a wire as an equator of Earth and a typical building behind for lectures), the teachers, as well as the students of the University approached their work with utmost enthusiasm. Under those impressions, I wrote an article to the biggest Vietnamese newspaper, Nhan Dan (Nation), from 13.02.1990 [3], in which I described Vinh University as "most unique among its worldly counterparts". 


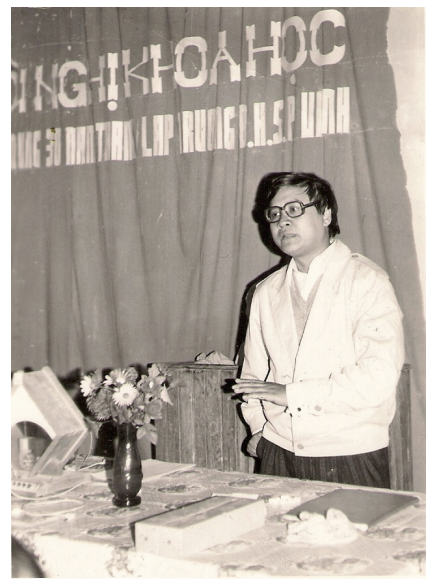

Phot. 2. At the 30-th anniversary celebration of Vinh University

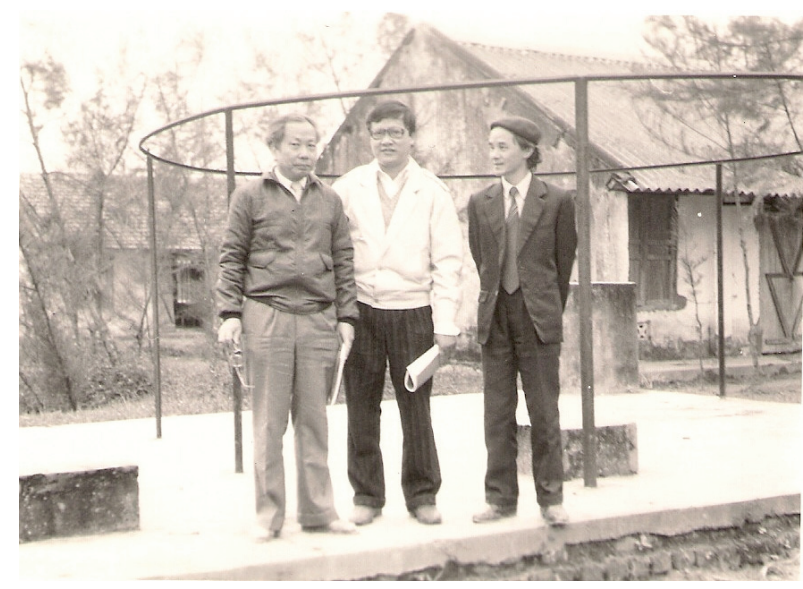

Phot. 3. With ex-presidents of Vinh University, Prof. Pham Quy Tu and Prof. Phan Ba Nhan on the "astronomical yard"

Simultaneously, I started to gather scientific staff for the Department of Physics. At that time, Vinh University was not authorised for postgraduation not only in physics, but also in other domains. Our common efforts led to the creation of the first commision for doctoral education in which another outstanding physicist, also ex-student of I. Białynicki-Birula, professor Kazimierz Rzażewski, had participated (Phot. 4). Another excellent ex-student of I. Bialynicki-Birula, professor Jan Mostowski, was one of the examinators for the first three postgraduate students. This "historical exam" was organised in the office of VCHMESON Company in Warsaw (with me holding the position of its General Director). That Company, the first Vietnamese-Polish joint venture in Poland, has promoted many Vietnamese scientists. Within the framework of its activity, many of them have been financially suported.
Professor J. Eberly remembered that student K. Wódkiewicz started his postgraduation in the United States having only 12 US dollars, but our PhD students Dinh Xuan Khoa, $\mathrm{Vu}$ Ngoc Sau and others started their education with the debit of nearly -107 USD (the cost of a flight from Vietnam to Poland)! The flight tickets were bought by a representative of the Vietnamese "Company of the new type" PROMETHIUM which was also created with my participation (I have described that Company in yet another article in Nation, in the issue from 19.01.1989 [4]). It was the only way of purchasing tickets which was accepted by the Vietnamese authorities of that time. My friends, K. Wódkiewicz, J. Mostowski (see Photos 5 and 6 of their letters) provided the Vietnamese students with the freedom of payment. However, the accomodation cost for their staying was formally covered by VCH-MESON Company.

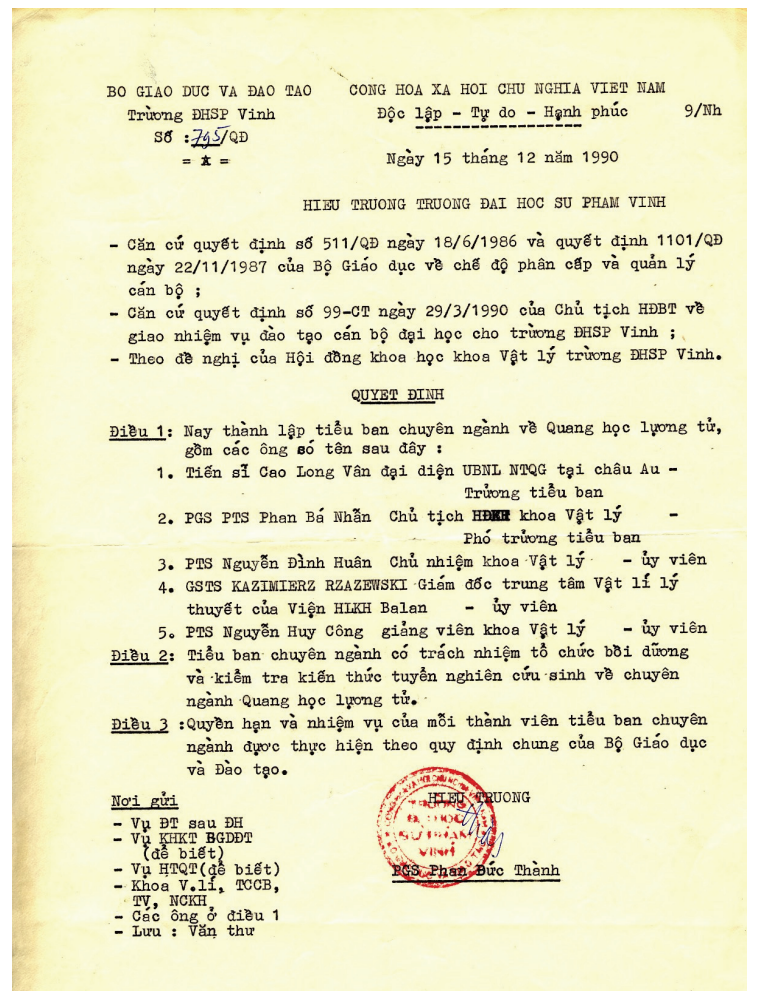

Phot. 4. First commision for doctoral education in Vinh University

My first postgraduate students defended their dissertations in 1996. In his letter to me in 1997, Dinh Xuan Khoa, recently a professor, and a vice-president of Vinh University, wrote:

“...The small fire sparkled by you will most certainly burst out into a big one...Your scientific grandsons and greatgrandsons are about to be born soon...". 


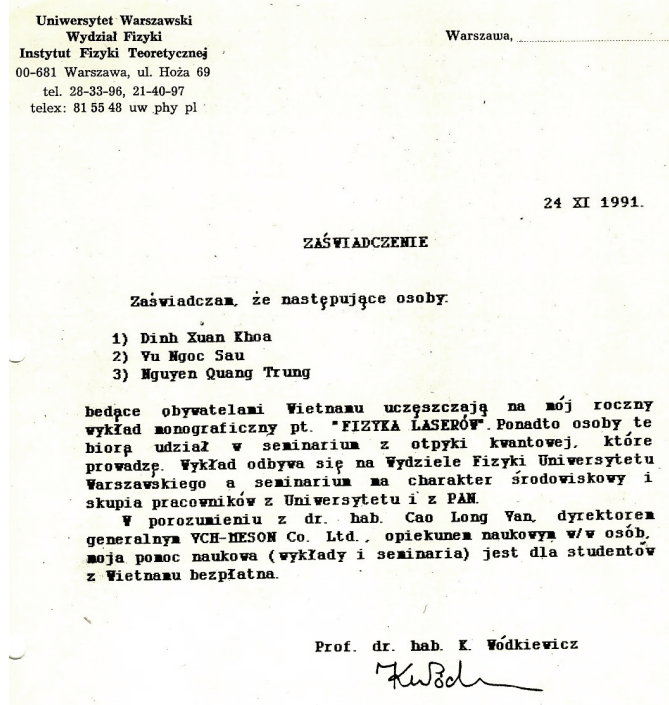

Phot. 5. Letter of Prof. K. Wódkiewicz

Warszawa, Decenber 2, 1991
Prof.dr hab. Jan Mostuwski
Institute of Fhysics
Polish Academy of Sciences
Aleja Lotników 32
02-668 Warszawa, Poland
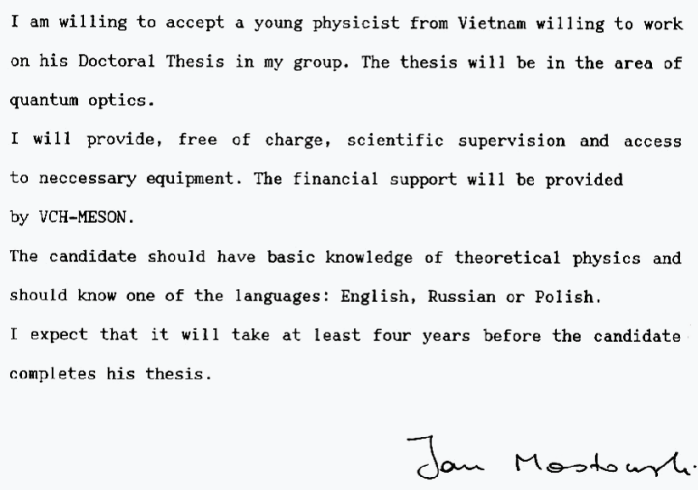

Phot. 6. Letter of Prof. J. Mostowski

The "School of Optics" in Vinh University is intensively developing since 2003, when the "scientific grandson" of I. Białynicki-Birula (a postgraduate student of K. Rzążewski) Prof. M. Trippenbach visited Vietnam and, along with me, gave a series of lectures from Nonlinear Optics (see Phot. 7). We extended the written version of these lectures into the book [5].

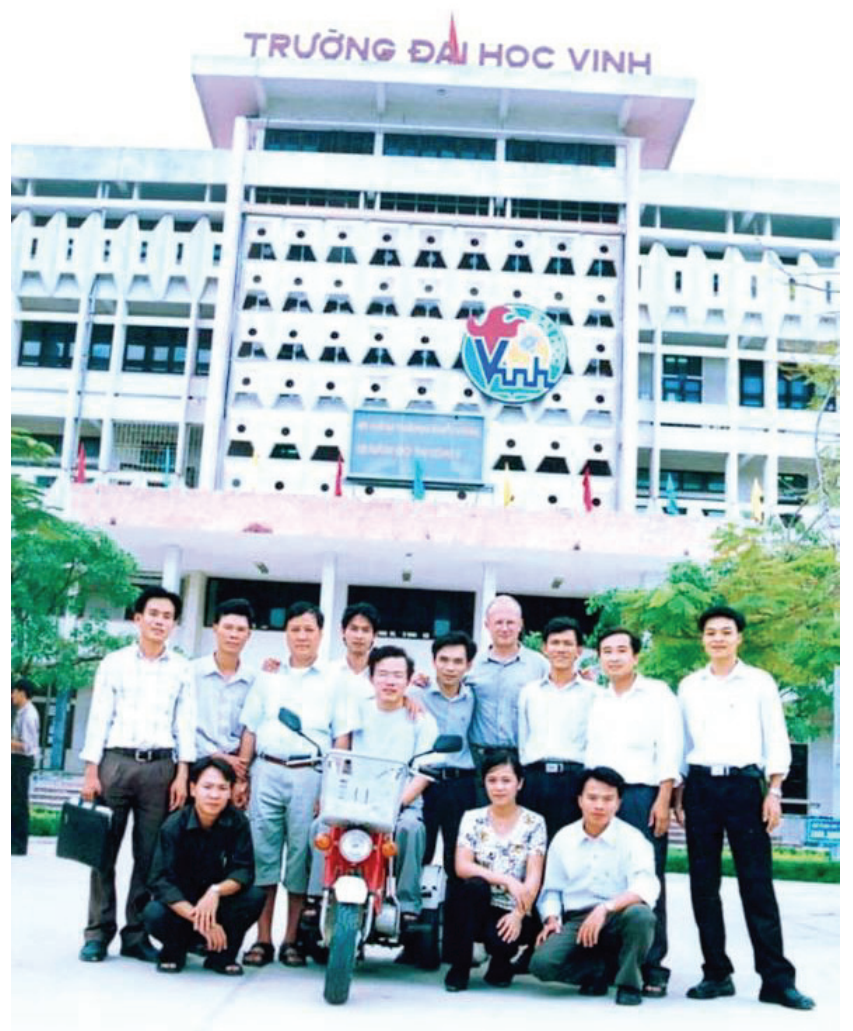

Phot. 7. Prof. M. Trippenbach in 2003

In 2005, my friend from Soltan Institute of Nuclear Studies in Warsaw, Dr. Piotr Goldstein was asked to give another series of lectures with me on Nonlinear Partial Differential Equations, which are the basis for our other book [6]. These lectures and those given by me on the course of several years, together with rich corespondence through the Internet effectively stimulates the education and research in Vinh University in the domain of Nonlinear and Quantum Optics. A review of some theoretical results will be presented in two papers in this issue [7, 8].

In his Nobel Lecture from May 23, 1924 Robert A. Millikian emphasized that "....Science walks forward on two feet, namely theory and experiment... Sometimes it is one foot which is put forward first, sometimes the other, but continuous progress is only made by the use of both by theorizing and then testing, or by finding new relations in the process of experimenting and then bringing the theoretical foot up and pushing it on beyond, and so on in inending alternation...". We also do not forget the "experimental foot". A long time ago, my friend, an outstanding experimentalist in Optics, Prof. Maciej Kolwas (recently holding the position of President of European Physical Society) offered his help for the Vietnamese students with 
freedom of payment (see Photo 8, this letter has not date of validity!). Under his warranty, a post-graduate student from Vinh University Nguyen Huy Bang under the direction of his supervisor Prof. Włodzimierz Jastrzębski from Institute of Physics, Polish Academy of Sciences succesfully defended his thesis on experimental optics a few months ago. Their results will be presented in one of this issue's articles [9]. For the sake of "inending alternation" in comparing theoretical results with the experimental one, as Millikian emphasized, we collaborated with the Warsaw Group in researching the well-known phenomenon:
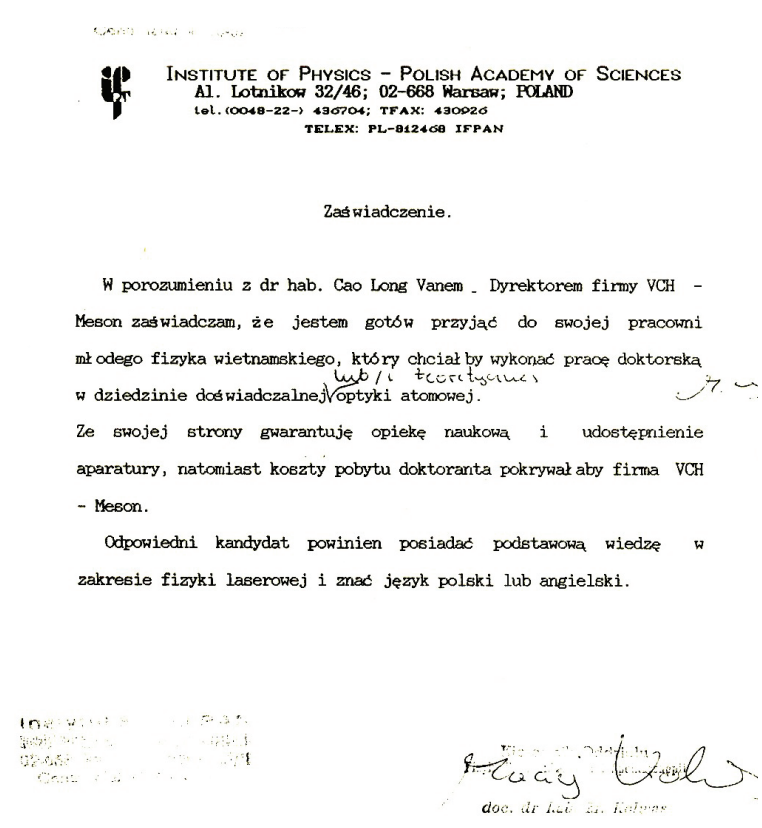

Phot. 8. Letter of Prof. M. Kolwas
Electromagnetically Induced Transparency. This is the subject of the paper [10] in this issue.

Now "School of Optics" in Vinh University has more than a dozen doctors, a few hundred masters with a few hundred scientific publications in Vietnam and abroad. In less than twenty years, it has sprouted from a seed, as Prof. Dinh Xuan Khoa wrote in his letter to me in 1997, into a full-grown tree. We deeply hope that in the near future it will become a famous Center for Optics not only in Vietnam but also in Asian South-Eastern Region.

\section{References}

[1] Cao Long Van, Krzysztof Wódkiewicz, Multiphoton ionisation in the presence of pre-Gaussian light. J. Phys. B: At. Mol. Phys. 19, 1925 (1986).

[2] Cao Long Van, Nguyen Huy Cong, (N-1)-resonant $N$ photon ionization in the presence of pre-Gaussian field. Acta Physica Polonica A76, 719 (1989).

[3] Cao Long Van, Some private investigations about education for young generation of scientists. Nhan Dan (Nation) 13.02.1990 (in vietnamese).

[4] Cao Long Van, Company PROMETHIUM, a new form of research and management in Science. Nhan Dan (Nation) 19.01.1989 (in vietnamese).

[5] Cao Long Van, Dinh Xuan Khoa, Marek Trippenbach, Introduction to Nonlinear Optics, Vinh University, Vinh 2003 (in vietnamese).

[6] Cao Long Van, Piotr P. Goldstein, A Concise Course in Nonlinear Partial Differential Equations, Zielona Góra 2008.

[7] Cao Long Van, Dinh Xuan Khoa, Marek Trippenbach, Nonlinear Optics of Photons and Atoms, paper in this issue.

[8] Cao Long Van et al., Propagation of ultrashort pulses in a nonlinear medium, paper in this issue.

[9] W. Jastrzębski, B. Nguyen Huy, unpublished presentation.

[10] K. Kowalski et al., Magneto-optical Trap: Fundamentals and Realization; K. Kowalski et al., Electromagnetically Induced Transparency, papers in this issue. 